\title{
KNR4, a suppressor of Saccharomyces cerevisiae cwh mutants, is involved in the transcriptional control of chitin synthase genes
}

\author{
Helene Martin, Adilia Dagkessamanskaia, Galina Satchanska, \\ Nathalie Dallies and Jean François
}

Centre de Bioingenierie Gilbert Durand, UMR-CNRS 5504, Lab. Ass. INRA, Departement de Genie Biochimique et Alimentaire, Complexe Scientifique de Rangueil, 31077 Toulouse Cedex 04, France

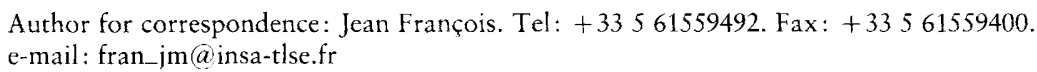

The KNR4 gene, originally isolated by complementation of a K9 killer-toxinresistant mutant displaying reduced levels of both $1,3-\beta$-glucan and $1,3-\beta$ glucan synthase activity, was recloned from a YCp50 genomic library as a suppressor of Saccharomyces cerevisiae calcofluor-white-hypersensitive (cwh) mutants. In these mutants, which were characterized by increased chitin levels, the suppressor effect of KNR4 resulted, for some of them, in a lowering of polymer content to close to wild-type level, with no effect on the contents of $\beta$-glucan and mannan. In all cases, this effect was accompanied by a strong reduction in mRNA levels corresponding to CHS1, CHS2 and CHS3, encoding chitin synthases, without affecting expression of FKS1 and RHO1, two genes encoding the catalytic subunit and a regulatory component of 1,3 - $\beta$-glucan synthase, respectively. Overexpression of KNR4 also inhibited expression of CHS genes in wild-type strains and in two other cwh mutants, whose sensitivity to calcofluor white was not suppressed by this gene. The physiological relevance of the KNR4 transcriptional effect was addressed in two different ways. In a wild-type strain exposed to $\alpha$-factor, overexpression of this gene inhibited CHS1 induction and delayed shmoo formation, two events which are triggered in response to the pheromone, whereas it did not affect bud formation and cell growth in a chs1 chs2 double mutant. A chimeric protein made by fusing green fluorescent protein to the $C$ terminus of Knr4p which fully complemented a knr4 $\Delta$ mutation was found to localize in patches at presumptive bud sites in unbudded cells and at the incipient bud site during bud emergence. Taken together, these results demonstrate that KNR4 has a regulatory role in chitin deposition and in cell wall assembly. A mechanism by which this gene affects expression of $\mathrm{CHS}$ genes is proposed.

Keywords: Saccharomyces cerevisiae, cell wall, chitin, KNR4, localization

\section{INTRODUCTION}

Yeasts and fungi are surrounded by a thick cell wall which accounts for $25 \%$ of the dry mass (Valentin $e t$ al., 1987; Fleet, 1991; Dallies et al., 1998). The cell wall is essential for maintenance of cell shape and offers protection against harmful environmental conditions. It is a dynamic structure which can adapt to different physiological states (conjugation, sporulation, station-

Abbreviations: DAPI, 4;6-diamidino-2-phenylindole dihydrochloride; GFP, green fluorescent protein. ary phase, etc.) and morphological changes (i.e. pseudohyphal and agar-invasive growth; Gimeno et al., 1992; Roberts \& Fink, 1994). It is composed of $\beta$-glucans and mannoproteins, which account for about $80-95 \%$ of wall dry mass, and of smaller amounts of chitin $(2 \%)$ and lipids (3-5\%) (for a review, see Klis, 1994).

Recently, genes involved in spatial and temporal cell wall construction in Saccharomyces cerevisiae have been the subject of intensive genetic research based on screening EMS-mutagenized (Ram et al., 1994) and transposon-mutagenized (Lussier et al., 1997) cells for increased sensitivity to calcofluor white, a cationic fluorescent dye known to interfere with cell wall 
assembly (Elorza et al., 1983). This work has led to the identification of more than 100 genes that can be roughly classified into four categories. The first class comprises structural genes for cell wall polymer biosynthesis. Chitin synthesis is governed by CHS1, CHS2 and CHS3, encoding the three membrane-bound chitin synthases, each of which is involved in a specific function in septum and cell wall construction in vegetative and conjugating cells (Cabib et al., 1996), and by regulatory components of these enzymes encoded by CHS4, CHS5 and CHS6 (Santos \& Snyder, 1997; Trilla et al., 1997; De Marini et al., 1997). Knowledge of $\beta$-glucan synthesis is less advanced but FKS1 and FKS2, encoding catalytic subunits of 1,3- $\beta$-glucan synthases have been characterized (Douglas et al., 1995; Inoue et al., 1995; Mazur et al., $1995)$, and a dozen genes involved in 1,6- $\beta$-glucan have been isolated on the basis of selection of mutants resistant to the K1 killer toxin (Klis, 1994; Cid et al., 1995). This category also includes MNN and ALG genes involved in the biosynthetic pathway leading to the formation of mannoproteins (Herscovics \& Orlean, 1993; Cid et al., 1995). Enzymes catalysing linkages between chitin and $\beta$-glucan, and those required for cell wall remodelling by association of cell wall proteins to 1,6- $\beta$-glucan through a glycosylphosphatidylinositol remnant (Cid et al., 1995; Kapteyn et al., 1997; Kollar et al., 1997) fall into a second category. Most of the genes in this category have not yet been identified. The third class contains genes involved in the signalling and morphogenetic pathways (budding, mating, polarized secretion, morphogenesis, sporulation; for a review, see Cid et al., 1995) and those which participate in the temporal and spatial control of cell wall formation needed for cell integrity/cell proliferation (Paravicini $e t$ al., 1992; Brown et al., 1993; Igual et al., 1997). The product of RHO1, controlling both the PKC1-MAP kinase pathway and 1,3- $\beta$-glucan synthesis represents one typical example of this class (Drgonova et al., 1997; Qadota et al., 1997). The fourth category comprises genes that cannot yet be included in any of the three previous classes, either because they encode proteins with other (vital) functions (ranging from involvement in metabolism, mitochondrial function, transcription, translation and DNA repair; Lussier et al., 1997) that undoubtedly have indirect effects on cell wall construction, or because they have been poorly characterized. This is notably the case with at least three genes, HKR1 (Kasahara et al., 1994), KNR4 (Hong et al., 1994a) and GNS1 (El-Sherbeini \& Clemas, 1995). Truncation of the $3^{\prime}$ part of the HKR 1 coding region or deletion of the KNR4 or GNS1 genes causes a reduction in both $1,3-\beta$-glucan synthase activity and $1,3-\beta$-glucan content. These findings have led to the conclusion that they are part of the regulatory mechanism for $\beta$-glucan synthesis. However, the great diversity in their localization [Gns1p is predicted to be an integral membrane protein (El-Sherbeini \& Clemas, 1995), Hkr1p, a surface protein (Yabe et al., 1996) and Knr4p a nuclear protein (Fishel et al., 1993)] makes a direct effect on $\beta$-glucan synthase activity very unlikely, and suggests a role in remodelling and assembly of cell wall polymers.
In this paper, we show that KNR4 was able to suppress several $S$. cerevisiae calcofluor-white-hypersensitive $(c w h)$ mutants, and report upon its effects on the expression of genes encoding chitin synthases and on its cellular localization.

\section{METHODS}

Strains and growth conditions. Yeast strains used in this study are listed in Table 1 . Yeast media contained either $2 \%(\mathrm{w} / \mathrm{v})$ Bactopeptone, $1 \%(\mathrm{w} / \mathrm{v})$ yeast extract and $2 \%(\mathrm{w} / \mathrm{v})$ glucose (YEPD) or $0.17 \%(\mathrm{w} / \mathrm{v})$ yeast nitrogen base without amino acids and ammonium, $0.5 \%(\mathrm{w} / \mathrm{v})$ ammonium sulphate and $2 \%(\mathrm{w} / \mathrm{v})$ glucose $(\mathrm{SD})$, supplemented with auxotrophic requirements. For solid media, agar (Difco) was added at $2 \%$ $(\mathrm{w} / \mathrm{v})$ final concentration. Yeast cultures were grown at $30^{\circ} \mathrm{C}$. Calcofluor white M2R (Sigma F6259) was freshly prepared as a stock solution of $10 \mathrm{mg} \mathrm{ml}^{-1}$ in water and filter-sterilized. The calcofluor-white-containing plates were made as follows: calcofluor white solution was added either to $\mathrm{SD}$ agar (buffered at $\mathrm{pH} 6.0$ with MES, $50 \mathrm{mM}$ ) or to YEPD agar media (both melted and kept at $70^{\circ} \mathrm{C}$ ) to a final concentration ranging from 0.05 to $1 \mathrm{mg} \mathrm{ml}^{-1}$. The $\mathrm{K} 9$-killer-toxin-containing plates were made according to the procedure of Hong et al. (1994a). Briefly, the strain Hansenula mrakii IFO0895 (a gift from Dr Didomenico, Shering-Plough Research Institute, NJ, USA) was grown for $72 \mathrm{~h}$ at $19^{\circ} \mathrm{C}$ in liquid YEPD medium, buffered with sodium citrate $0 \cdot 1 \mathrm{M}, \mathrm{pH} 4 \cdot 7$. Cells were collected by centrifugation and the culture medium was sterilized by filtration. Aliquots $(5 \mathrm{ml})$ of filtered culture medium were added to $20 \mathrm{ml}$ YEPD agar (buffered with sodium citrate, $0.1 \mathrm{M}, \mathrm{pH} 4.7$; melted and kept at $55^{\circ} \mathrm{C}$ ).

Transformation of calcofluor-white-hypersensitive mutants with a YCp50 library. Transformation of calcofluor-white hypersensitive-mutants ( $c w h$ mutants) was carried out by the standard LiAc method (Schietsl \& Gietz, 1989), using a genomic library of S. cerevisiae constructed in YCp50 (Rose et al., 1987) and purchased from ATCC (accession number $37415)$. Transformed cells were directly plated on SD medium without uracil (SD - uracil) containing $0.1 \mathrm{mg}$ calcofluor white $\mathrm{ml}^{-1}$, since preliminary assays indicated that the $c w h 43-2$ mutant cells displayed almost no growth on these plates after $2 \mathrm{~d}$ at $30^{\circ} \mathrm{C}$ whereas the wild-type control AR27 grew very well. Colonies (about 20 out of 90000 expected URA ${ }^{+}$ transformants) were further screened on plates containing a higher calcofluor white concentration before and after the loss of $U R A^{+}$-containing plasmids [on media containing $0 \cdot 1 \% 5$ fluoroorotic acid (5-FOA; Boeke et al., 1987)]. Plasmids conferring resistance to calcofluor white were isolated according to Robzyk \& Kassir (1992) and sent for partial sequencing (Genome Express, Grenoble, France). From the DNA sequences, homology searches in the yeast genomic sequence databases [SGD (Standford Genomic Database, USA) or MIPS (Martinsried Institute for Protein Sequences, Germany); Mewes et al., 1997] were conducted to identify the chromosomal location of the DNA fragments and the ORFs present on these fragments. Putative ORFs with about $1 \mathrm{~kb}$ of $5^{\prime}$ and $3^{\prime}$ flanking regions were subcloned in centromeric pRS316 and episomic pRS426 derivative plasmids (Sikorski \& Hieter, 1989; Christianson et al., 1992) and checked for their ability to complement the calcofluor white sensitivity phenotype of the mutants.

Plasmid and strain construction. A $2.95 \mathrm{~kb}$ XbaI-SpeI fragment containing KNR4 was cut from one of the genomic library inserts and cloned into the SpeI site of the episomic pRS426 and centromeric pRS316 shuttle vectors to yield 
Table 1. S. cerevisiae strains used in this work

\begin{tabular}{|c|c|c|}
\hline Strain & Genotype & Reference or source \\
\hline AR27 & MAT $\alpha$ ura3-52 & \multirow{10}{*}{ Ram et al. (1994) } \\
\hline AR27-2N & MAT $\alpha / M A T$ a $u r a 3-52 /$ ura3-52 & \\
\hline cwh3 & AR27 cwb3 & \\
\hline cwh4 & $\operatorname{AR} 27 c w b 4$ & \\
\hline cwh5 & AR27 cwh5 & \\
\hline cwh9 & AR27 cwb9 & \\
\hline cwh39 & AR27 cwh39 & \\
\hline cwh43-1 & AR27 cwb43-1 & \\
\hline cwh43-2 & AR27 cwh43-2 & \\
\hline cwh53-1 & AR27 cwh53-1 & \\
\hline HM10 & AR27 $k n r 4:: k a n^{\mathrm{R}}$ & This study \\
\hline HM20 & AR27-2N KNR $4:: k n r 4:: k a n^{\mathbf{R}}$ & This study \\
\hline ECY36-3C & MAT $\alpha-$ chs1-23 chs $2::$ LEU2 leu2-2 ura3-52 trp1-1 & Choi et al. (1994) \\
\hline
\end{tabular}

pHM37 and pHM38, respectively. To construct a gene fusion encoding the full-length $\mathrm{Knr} 4 \mathrm{p}$ fused to the green fluorescent protein (GFP) (Chalfie et al., 1994), the ORF of KNR4 was amplified by PCR using Vent DNA polymerase (New England Biolabs) with the primers $5^{\prime}$ CGCGCGACTAGTATGGATCTATTCAAAAGAAAAGTT $3^{\prime}$ and $5^{\prime}$ GCGCGCAAGCTTTAAAGCTATATTTTCAAATTCTTC 3', containing SpeI and HindIII sites (underlined). The PCR product was digested with these restriction endonucleases and ligated into the SpeI/HindIII-digested centromeric pGFP-C-FUS plasmid (Niedenthal et al., 1996) resulting in pGFP-C-KNR4. A disruption cassette for KNR4 was made by insertion of a blunt-end fragment of the $k a n^{\mathrm{R}}$ gene into the Ebe 1 site of KNR4 in pHM37. The cassette was excised with Spe1 and Nde1, and used to transform strain AR27. Verification of the correct integration at the KNR4 locus was carried out by PCR amplification using primers 5' GAGTCATCTTGGATAATGAAGC $3^{\prime}$ and $5^{\prime}$ CCCCATCACTCCACTCCCCATC $3^{\prime}$. A plasmid with the KNR4 gene under the control of the GAL10/CYC1 promoter was constructed by cloning a PCR-amplified KNR4 ORF into the BamHI and EcoRI sites of pYEDP60-2 (Pompon et al., 1996) using the two primers with sequence identical to those used for making the GFP-C-KNR4 fusion gene, except that the SpeI and HindIII sites were replaced by $B a m \mathrm{HI}$ and EcoRI sites, respectively.

RNA analysis. Total RNA was extracted from exponentially growing cells (OD ${ }_{600} 1.5$ ), separated in formaldehyde agarose gels as described by Siderius et al. (1997) and transferred to Hybond- $\mathrm{N}^{+}$filters (Amersham). Hybridization and washings were performed as recommended by the manufacturer. Blots were probed with the following restriction fragments: a $1.5 \mathrm{~kb}$ BamH1-HindIII fragment of ACT1 from plasmid pJJ16 (a gift from Dr C. Gancedo, CSIC, Madrid, Spain), which was used as a loading control; a $2 \mathrm{~kb}$ EcoRV-Stu 1 fragment of CHS1 from pAS1; a $1.9 \mathrm{~kb}$ Stu 1 fragment of CHS2 from pEC2; a $2.4 \mathrm{~kb}$ Xhol-HindIII fragment of CHS3 from $\mathrm{pHV} 8$ (these three latter plasmids were a gift from E. Cabib, NIH, Bethesda, $\mathrm{MD}$, USA); a $2 \cdot 1 \mathrm{~kb}$ XbaI-ClaI fragment of FKS1 (a gift from F. M. Klis, University of Amsterdam, The Netherlands); a $1.3 \mathrm{~kb}$ fragment of RHO1 (obtained from the YCp50 genomic library as one of the suppressors of the cwh43-2 mutation, unpublished results). The fragments were radiolabelled with ${ }^{32} \mathrm{P}$ using the Megaprime DNA labelling system (Amersham).

Phenotypic tests. Yeast cells were grown overnight in liquid $\mathrm{SD}-$ uracil or YEPD to $\mathrm{OD}_{530} \sim 4 \cdot 0$, concentrated by centri- fugation and resuspended in sterile water to $\mathrm{OD}_{530} 8 \cdot 0$. Serial dilutions of $1 / 1,1 / 10,1 / 100$ and $1 / 1000$ were spotted on solid media containing either calcofluor white or $\mathrm{K} 9 \mathrm{killer}$ toxin. Growth was scored after $2 \mathrm{~d}$ incubation at $30^{\circ} \mathrm{C}$.

Treatment with $\boldsymbol{\alpha}$-factor. MATa cells were grown to early exponential phase $\left(\mathrm{OD}_{600} 0 \cdot 2\right)$ in liquid YEPD medium to which $\alpha$-factor (Sigma T6901; $1 \mathrm{mM}$ in methanol) was added to a final concentration of $2 \times 10^{-6} \mathrm{M}$. Samples for RNA isolation and for counting shmoos were taken at different times as indicated in Fig. 4.

Quantitative cell wall carbohydrate analysis. The sugar composition of cell walls was determined from exponential cultures of yeast cells grown in SD - uracil and harvested at $\mathrm{OD}_{600} 1 \cdot 0$. Isolation of cell walls, hydrolysis of cell wall polymers in $\mathrm{H}_{2} \mathrm{SO}_{4}$ and quantification of the liberated sugars (glucose, mannose, glucosamine) were carried out as described by Dallies et al. (1998).

Observation by fluorescence microscopy. Localization of the Knr4-GFP fusion protein was visualized in living cells from strain AR27 deleted for KNR4 and transformed with the centromeric plasmid pKnr4-C-GFP. Cells were grown exponentially in liquid SD medium supplemented with auxotrophic requirements. Cells were viewed with a Zeiss Axiophot 2 microscope using the filter combination 450-490, FT510, BP 515-565 and to prevent movement during visualization, yeast cells were mounted in $0.05 \%(\mathrm{w} / \mathrm{v})$ agarose. For staining nuclei, living cells were incubated for $1 \mathrm{~h}$ in DAPI (4',6-diamidino-2-phenylindole dihydrochloride; $2.5 \mathrm{mg}$ $\left.\mathrm{ml}^{-1}\right)$.

\section{RESULTS}

\section{KNR4 is a suppressor of a number of calcofluor- white-hypersensitive mutants}

Klis and coworkers (Ram et al., 1994) isolated 63 calcofluor-white-hypersensitive mutants that were classified into 53 complementation groups. Two of them, cwh43-1 and cwh43-2, were given to us in order to clone wild-type genes by complementation. The cwh43-2 mutation was mapped on chromosome III between the LEU2 and MAT loci (unpublished data). The transformation of this mutant with a genomic library in YCp50, (Rose et al., 1987) followed by selection on SD 


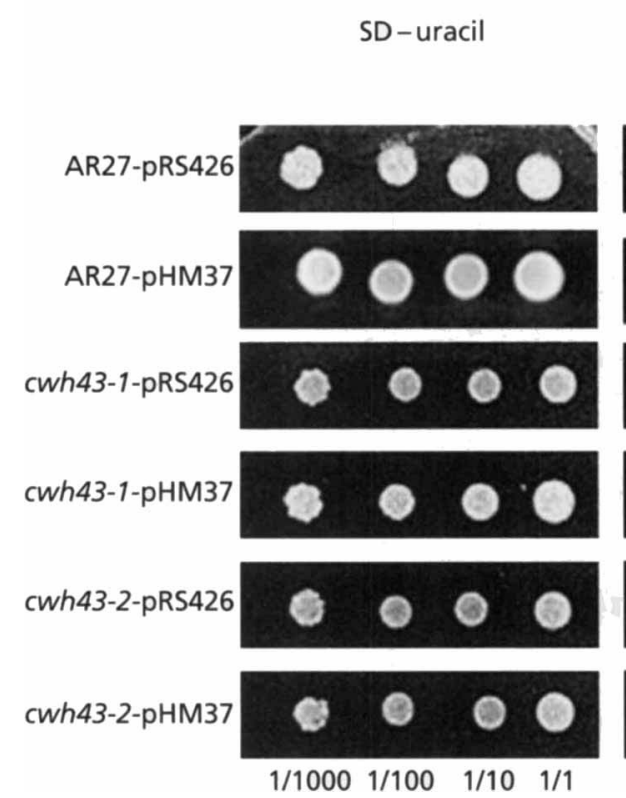

SD-uracil

+ calcofluor white

$\left(0.25 \mathrm{mg} \mathrm{ml}^{-1}\right)$
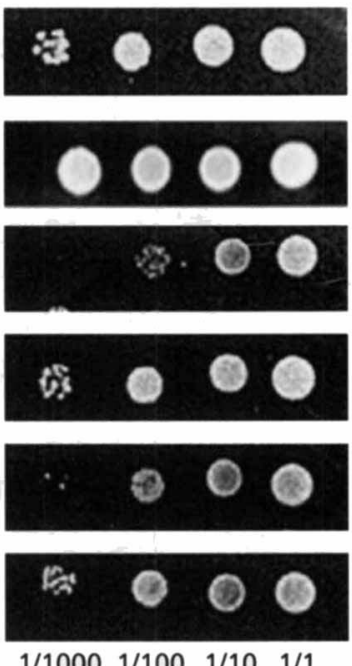

Fig. 1. Suppression of cwh mutants by KNR4. Transformed wild-type, cwh43-1 and cwh43-2 mutant strains with either pRS426 (control plasmid) or pHM37 (pRS426 containing KNR4) were grown overnight on $S D$ - uracil and concentrated to $O D_{530} 8.0$. Serial dilutions of yeast cultures were spotted on SD - uracil plates in the absence or presence of $0.25 \mathrm{mg}$ calcofluor white $\mathrm{ml}^{-1}$. Growth was scored after $2 \mathrm{~d}$ at $30^{\circ} \mathrm{C}$.
- uracil containing $0 \cdot 10 \mathrm{mg}$ calcofluor white $\mathrm{ml}^{-1}$ gave rise to six complementing plasmids, among which two contained overlapping 10-14 kb fragments from chromosome VII with several ORFs, including KNR4. This gene, subcloned in either a centromeric or a multicopy plasmid, was able to restore wild-type sensitivity of the cwh43-2 mutant strain to calcofluor white (Fig. 1). We also found that KNR4 could suppress the cwh43-1 mutation, which was initially claimed to be allelic to cwh43-2 (Ram et al., 1994). However, we could not confirm this allelism as the diploid mutant obtained by crossing the two haploid mutants was as sensitive to the drug as the wild-type, and the cwh43-1 mutation did not show any linkage with markers from chromosome III. Fig. 1 also shows that the control strain AR27 bearing additional copies of KNR4 was more resistant to calcofluor white. These results suggested that the complementation by KNR4 was not restricted to a specific interaction with the cwb43-2 mutation.

To confirm this hypothesis, the centromeric and episomic plasmids bearing KNR4 were used to transform $c w h$ mutants originally classified as having a cell wall mannose/glucose ratio lower than that of the wild-type, and a few others with a mannose/glucose ratio higher than that of the wild-type (Ram et al., 1994), in order to determine whether complementation occurred independently of changes in mannose/glucose ratios. From a series of cwh mutants, three mutants (cwh5, cwh), cwh43-2) with lower levels of mannan and three others (cwh4, cwh39, cwh43-1) having slightly lower levels of $\beta$-glucan, as compared to those in the control strain AR27 were suppressed by KNR4 borne on a multicopy plasmid (Table 2).

Because KNR 4 borne on a centromeric plasmid was also known to be able to suppress the calcofluor white sensitivity of some of the cwh mutants tested, it was suggested that a small change in the amount of
Knr4p affects cell wall structure. In favour of this interpretation, we found that the deletion of one copy of KNR4 in a diploid rendered this strain sensitive to calcofluor white, and that the sensitivity to this drug was more pronounced in a haploid strain deleted for this gene (Fig. 2) and in a diploid strain homozygous for $\Delta k n r 4$ (not shown). In addition, and in contrast to a previous report of Fishel et al. (1993) who cloned the same gene (named SMI1 for suppressor of MAR inhibition 1), deletion of this gene did not result in a thermosensitive growth arrest phenotype in two different genetic backgrounds.

\section{Changes in cell wall composition induced by additional copies of $K N R 4$}

Since calcofluor sensitivity is basically dependent on the chitin content of the cells, we analysed the cell wall composition in $c w h$ mutants transformed with control and KNR4-containing plasmids. Results of these measurements are shown in Table 2. It can be seen that, except for the $c w h 39$ and $c w b 43-1$ mutant strains, other $c w h$ mutants transformed with the control plasmid (pRS426) contained two- to fivefold more chitin than the control strain AR27. This result agrees with previous data showing that modifications leading to changes in cell wall content of either mannan or glucan are accompanied by an increase in chitin (Daran et al., 1997; Popolo et al., 1997; Kapteyn et al., 1997; Dallies et al., 1998). Upon transformation with the multicopy plasmid pHM37, one group of four cwh mutants which were complemented by KNR4 showed a significant decrease in chitin levels. In a second group of two mutants also complemented by this gene, changes in chitin levels were barely detectable. In a third group of two cwh mutants which were not complemented by KNR4, one of them (cwh3) showed reduced levels of chitin in the presence of additional copies of $K N R 4$, whereas in the other (cwh53- 
Table 2. Effect of overexpression of KNR4 on cell wall carbohydrate composition of control and cwh mutant strains

Cell walls were obtained from exponentially growing cells cultivated on SD - uracil. Results are expressed as percentages of cell wall dry mass and values are the means from two independent experiments. The standard deviation was $5 \%$. ND, Not determined.

\begin{tabular}{|c|c|c|c|c|c|c|c|}
\hline \multirow[t]{2}{*}{ Strain } & \multirow{2}{*}{$\begin{array}{l}\text { Complementation } \\
\text { by KNR } 4\end{array}$} & \multicolumn{2}{|c|}{ Glucan } & \multicolumn{2}{|c|}{ Mannan } & \multicolumn{2}{|c|}{ Chitin } \\
\hline & & pRS426 & pHM37 & pRS426 & pHM37 & pRS426 & pHM37 \\
\hline cwh5 & + & $68 \cdot 1$ & $70 \cdot 3$ & $26 \cdot 2$ & $26 \cdot 6$ & $5 \cdot 6$ & $3 \cdot 0$ \\
\hline cwh9 & + & $73 \cdot 1$ & $70 \cdot 2$ & $22 \cdot 0$ & $25 \cdot 8$ & $4 \cdot 9$ & $4 \cdot 0$ \\
\hline cwh43-2 & + & $65 \cdot 3$ & $65 \cdot 0$ & $28 \cdot 2$ & $31 \cdot 4$ & $6 \cdot 5$ & $3 \cdot 6$ \\
\hline cwh4 & + & $53 \cdot 4$ & $62 \cdot 0$ & $41 \cdot 0$ & $34 \cdot 2$ & $4 \cdot 7$ & $3 \cdot 8$ \\
\hline cwh39 & + & $55 \cdot 7$ & $60 \cdot 0$ & $42 \cdot 2$ & $37 \cdot 7$ & $2 \cdot 1$ & $2 \cdot 3$ \\
\hline cwh43-1 & + & $58 \cdot 5$ & $49 \cdot 4$ & $39 \cdot 2$ & $49 \cdot 1$ & $2 \cdot 5$ & $2 \cdot 5$ \\
\hline cwh3 & - & $62 \cdot 8$ & $72 \cdot 1$ & $32 \cdot 4$ & $24 \cdot 0$ & $4 \cdot 8$ & $4 \cdot 0$ \\
\hline cwh53-1 & - & $37 \cdot 7$ & $35 \cdot 0$ & $47 \cdot 9$ & $50 \cdot 7$ & $14 \cdot 4$ & $14 \cdot 3$ \\
\hline AR27 & ND & $59 \cdot 3$ & ND & $38 \cdot 0$ & $\mathrm{ND}$ & $2 \cdot 7$ & ND \\
\hline
\end{tabular}

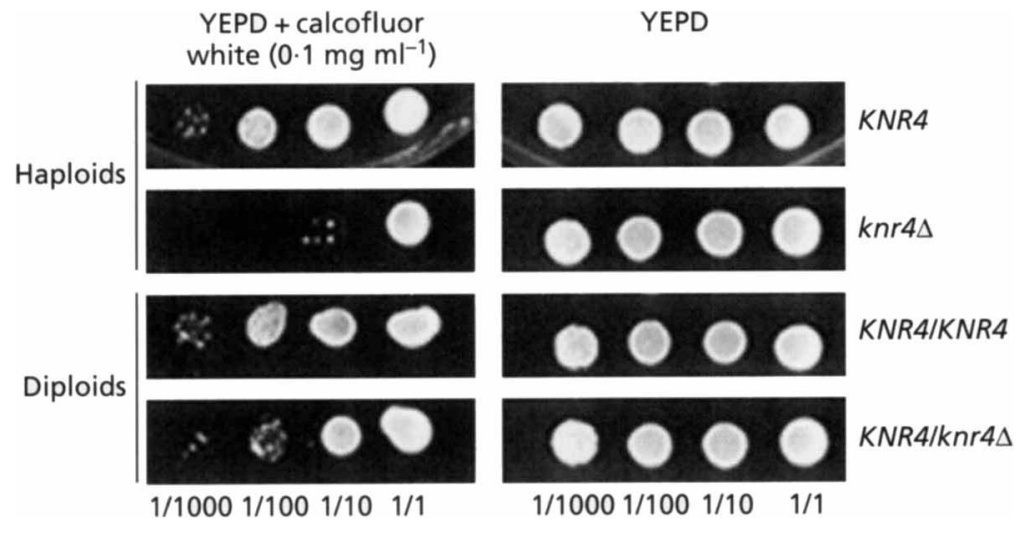

Fig. 2. Effect of a KNR4 deletion in haploid and isogenic diploid strains on their sensitivity to calcofluor white. Strains were grown overnight on YEPD to stationary phase and concentrated to $\mathrm{OD}_{530} 8.0$. Serial dilutions were spotted on YEPD plates in the absence or presence of $0.1 \mathrm{mg}$ calcofluor white $\mathrm{ml}^{-1}$.
1) mutant bearing a mutation in FKS1, (encoding the catalytic subunit of 1,3- $\beta$-glucan synthase; Ram et al., $1995)$, no effect on chitin levels could be detected. It can also be seen in Table 2 that the effects of overexpressing KNR4 on mannan and glucan levels were moderate, specific to each mutant strain, and that no link between changes in these two cell wall polymers and the suppressor effect of this gene could be found.

Since the KNR4 suppressor effect was observed on media containing calcofluor white, the presence of which is known to increase chitin levels (Roncero \& Duran, 1985), we thought that additional copies of KNR4 would antagonize this increase, and therefore could account for the complementation of cwh mutants by this gene. If this was the case, the effect of additional copies of the gene on chitin levels would be more pronounced in the presence of calcofluor white. Unfortunately, attempts to conduct cell wall analysis with yeast grown in the presence of $0.1 \mathrm{mg}$ calcofluor white $\mathrm{ml}^{-1}$ failed because of the formation of a large amount of yellow precipitate resistant to hot acidic hydrolysis. Different methods to dissolve this precipitate were unsuccessful.

\section{Effect of KNR4 on the transcription of genes encoding chitin synthases}

The fact that on one hand, a deletion of KNR4 resulted in a fourfold increase in chitin content and a $50 \%$ decrease in $\beta$-glucan content, and that on the other hand, additional copies of this gene suppressed the calcofluor white sensitivity of yeast mutants associated, in some cases, with reduction in cell wall chitin prompted us to investigate the effect of KNR4 on the transcription of key genes involved in cell wall polymer biosynthesis by Northern analysis. As shown in Fig. 3, transcripts for CHS1, CHS2 and CHS3, encoding chitin synthases, were strongly reduced both in the control strain AR27 and in cwh mutants transformed with either a centromeric vector or an episomic vector bearing KNR4. There was, however, no effect on expression of FKS1 


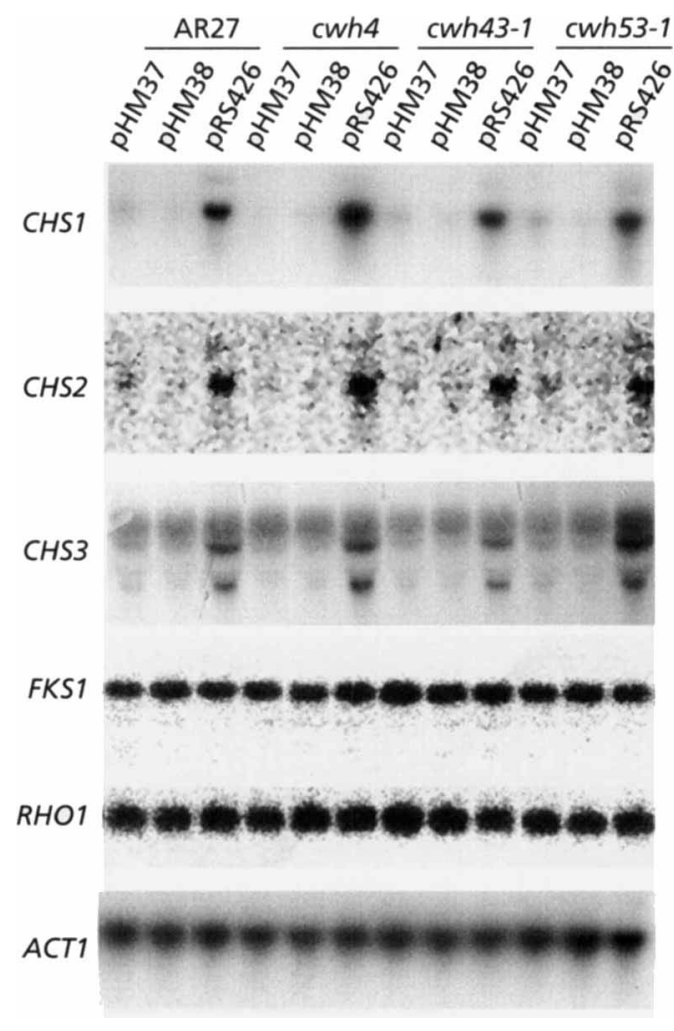

Fig. 3. Effect of overexpression of KNR4 on expression of CHS1. CHS2, CHS3, FKS1 and RHO1. Total RNA (15 $\mu \mathrm{g}$ per lane) was analysed by Northern blot experiments as outlined in Methods. $A C T 1$ transcripts were used as a loading control.

and RHO1. Interestingly, the repressing effect of additional copies of KNR4 was observed in all mutant strains, even in those that were not complemented by this gene. The case of the cwh53-1 mutant is particularly striking. Although this mutant strain contained a huge amount of chitin, mRNA corresponding to the three $\mathrm{CHS}$ genes was not higher than in the wild-type control. In contrast, the overexpression of KNR4 in the cwh531 mutant was without effect on chitin, though it caused a strong reduction in CHS transcripts (Fig. 3). We also found that deletion of KNR4 in the control strain AR27 caused a fourfold increase in chitin levels without changing the expression pattern of CHS genes (results not shown).

\section{Additional copies of $K N R 4$ affect pheromonal response in a wild-type strain but not the growth of a chs1 chs2 double mutant}

To illustrate a potential physiological role of KNR4 in regulating expression of $C H S$ genes, we investigated the effect of overexpressing this gene on the induction of CHS1 (Appeltauer \& Achstetter, 1989) and shmoo formation of haploid cells in response to pheromone. Fig. 4 shows that activation of CHS1 was strongly inhibited, and shmoo formation was delayed in these (a)

\begin{tabular}{|ccc|}
\hline $\begin{array}{c}\text { Time after addition } \\
\text { of } \alpha \text {-factor }(\mathrm{h})\end{array}$ & \multicolumn{2}{c|}{ Percentage of shmoos formed } \\
\cline { 2 - 3 } & AR27-pHM37 & AR27-pRS426 \\
\hline 0 & 0 & 0 \\
1 & 0 & 9 \\
2 & 39 & 79 \\
3 & 52 & 82 \\
4 & 69 & 83 \\
5 & 74 & 85 \\
\hline
\end{tabular}

(b)

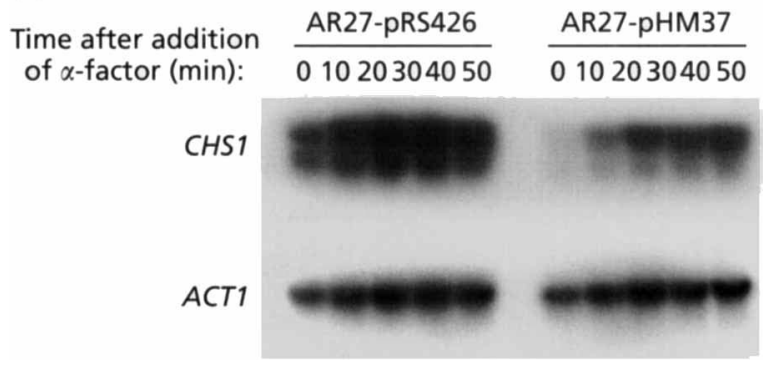

Fig. 4. Effect of overexpression of KNR4 on shmoo formation and induction of CHS1 upon exposure of yeast to $\alpha$-factor. Exponentially growing cells of strain AR27 transformed with pRS426 (control plasmid) or pHM37 (pRS426 containing KNR4) on SD-uracil were exposed to $2 \times 10^{-6} \mathrm{M} \alpha$-factor. (a) The percentage of shmoos was determined by counting about 300 cells under the optical microscope. (b) Induction of CHS1 in response to mating pheromone was analysed by Northern blots of CHS1 mRNA. The blot was also hybridized with ACT1 probe used as a loading control.

MATa cells bearing multicopies of KNR4 incubated with $2 \times 10^{-6} \mathrm{M} \alpha$-factor. This delay was most likely due to the effect of additional copies of KNR4 in reducing levels of CHS2 and CHS3 transcripts in transformed cells since recent data have shown no relationship between CHS1 expression and mating efficiency (Santos et al., 1997). To further strengthen a potential role of KNR4 in chitin formation, we transformed a chs 1 chs 2 double mutant which can survive due to the presence of CHS3 with pHM37 bearing KNR4 on a multicopy vector. As expected, the levels of CHS3 transcript were dramatically reduced, in a similar way to that illustrated in Fig. 3, with no detectable effect on bud formation or on cell growth (results not shown). The same results were obtained for a chs 2 chs 3 double mutant strain transformed with a plasmid bearing KNR4 under the control of the GAL10/CYC1 hybrid promoter upon transfer from a glucose- to a galactose-containing medium.

\section{Localization of KNR4 using the GFP fusion protein}

In previous work aimed at identifying genes involved in chromatin reorganization during mitosis, a gene named SMI1 $100 \%$ identical to KNR4 was isolated (Fishel et al., 1993). These authors generated anti-SMI1 antibodies 


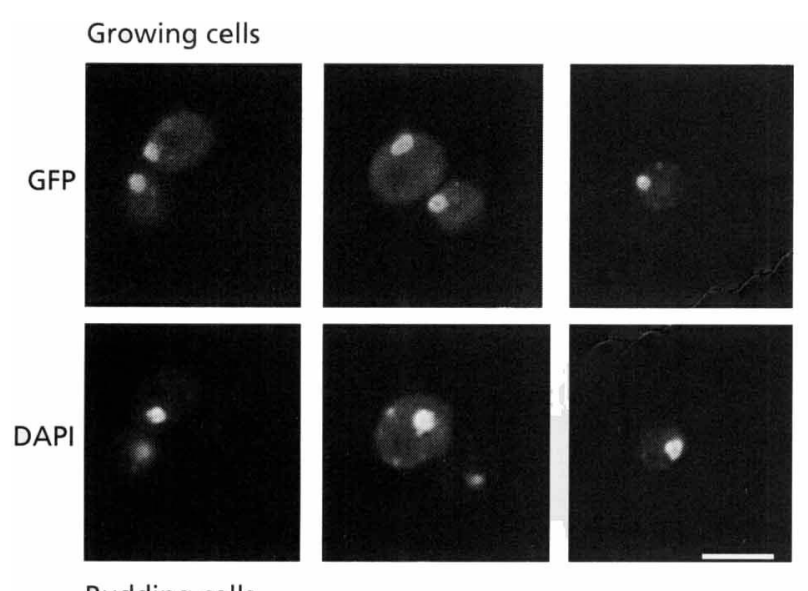

Budding cells
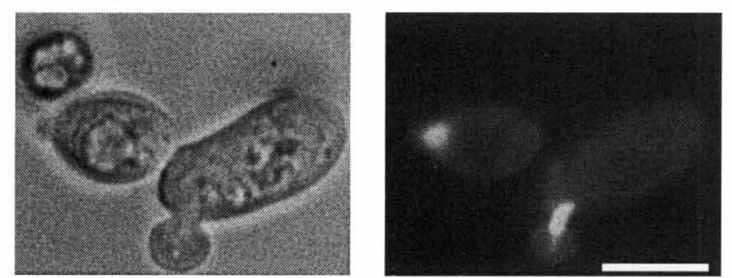

GFP

Fig. 5. Localization of GFP-Knr4p fusion protein in a $\Delta k n r 4$ strain transformed with pGFP-KNR4. Cells of strain HM10 were grown, fixed and visualized as described in Methods. Time exposure for GFP-fusion protein was $15 \mathrm{~s}$, and for DAPI $2 \mathrm{~s}$. Bar, $5 \mu \mathrm{m}$.

raised against 18 amino acids of the $\mathrm{C}$ terminus region of the protein to use for immunolocalization in animal cells. As these antipeptide antibodies reacted with intranuclear materials, these authors concluded that Smi1p homologues exist in the nucleus of animal cells (Fishel et al., 1993). Very surprisingly, they did not use these anti-SMI1 antibodies for indirect immunofluorescent experiments in yeast. Therefore, we reinvestigated the cellular localization of the SMI1/KNR4 gene product in yeast cells, using the GFP fusion methodology (Chalfie et al., 1994). To this end, we constructed two centromeric plasmids, one with GFP at the $\mathrm{C}$ terminus, and the other at the $\mathrm{N}$ terminus of Knr4p. Only the first construction turned out to be functional since it fully complemented a $\Delta k n r 4$ strain for the ability to restore wild-type sensitivity to calcofluor white and to K9 killer toxin. Transformed cells growing exponentially on SD medium without methionine were examined by fluorescence microscopy. This experiment revealed that the fusion protein localized as cytoplasmic patches near the presumptive bud site in unbudded cells, distinct from the nucleus (top left of Fig. 5), and that it localized at the incipient bud site in cells with small buds (bottom right of Fig. 5). During growth of the daughter cells, the GFP-Knr4p remained in the neck of the bud. Before nuclear division, the fusion protein separated into two parts, with one migrating to the cytoplasm of the daughter cell and the other remaining in the mother cell (not shown). The same results were obtained with cells growing in the presence of methionine, except that the fluorescence intensity was weaker.

\section{DISCUSSION}

We report in this paper that additional copies of the KNR4 gene can suppress the calcofluor white hypersensitivity of several cwh mutants. Although the loss of function of this gene caused a $50 \%$ decrease in $\beta$-glucan (Hong et al., 1994a), the suppressor effect of overexpression of KNR 4 could not be explained by partial recovery of this cell wall polymer because it was obtained with mutants containing $\beta$-glucan levels at both lower and higher levels than those of the control strain. As it was recently shown that changes in either $\beta$ glucan or mannan in yeast cell walls were accompanied by an increase in chitin levels (Popolo et al., 1997; Dallies et al., 1998), and as the perturbating effect of calcofluor white on cell wall assembly is caused by its binding to chitin (Elorza et al., 1983), we suggested that additional copies of KNR4 might cause a decrease in chitin levels in $c w h$ mutants. Hence, this would make these mutant strains less sensitive to calcofluor white, simply because they would have fewer binding sites for the drug. In addition, this suggestion was supported by the fact that deletion of KNR4 led to a fourfold increase in chitin (Hong et al., 1994b). Quantitative cell wall analysis showed that additional copies of KNR4 actually lowered the chitin content in the wall of some, but not all, cwh mutants. We believe that this effect was not observed in all cases because the experiments were performed with cells grown in the absence of calcofluor white, whose presence is known to activate chitin polymerization (Roncero \& Duran, 1985). Therefore, the decreased sensitivity of $c w h$ mutants overexpressing KNR4 could be due to its effect of counteracting the increase in chitin in mutants cultivated in the presence of calcofluor white. Unfortunately, this hypothesis could not be verified because of an inability to extract the sugar components of cell walls from yeast cultivated under this condition.

To further understand how KNR4 could affect cell wall assembly, we studied the expression of key genes involved in biosynthesis of chitin and 1,3- $\beta$-glucan in yeast cells deleted for KNR4 and in those containing additional copies of this gene. The results of these experiments showed that as the transcripts corresponding to genes encoding the three membrane-bound chitin synthases were severely reduced in cells containing at least one additional copy of KNR4, chitin levels were either reduced or unchanged. This was particularly the case with the cwh53-1 mutant, as its very high content of chitin was not affected by overexpression of KNR4, despite a strong decrease in CHS transcripts. In contrast, the message levels of these three genes were not modified in a $\Delta k n r 4$ mutant, even though the chitin content in this mutant was increased fourfold. Moreover, deletion or overexpression of KNR4 did not affect expression of FKS1 and RHO1, two genes involved in 1,3- $\beta$-glucan 
synthesis. Taken together, these results indicate that there is no proportional correlation between CHS mRNA and chitin levels, and that cell wall modifications induced by changes in the amount of Knr4p cannot be solely mediated by transcriptional effects on the genes encoding key enzymes in the biosynthesis of cell wall polymers. Furthermore, the transcriptional down regulation of CHS genes by KNR4 does not seem to have important physiological relevance for chitin biosynthesis because the potent repression of CHS3 expression in a chs 1 chs 2 double mutant (ECY36-3C) by KNR4 overexpression was not accompanied by any detectable effect on bud formation, cell morphology and vegetative growth. These data suggest that chitin biosynthesis is not merely regulated at the transcriptional level. A similar conclusion was given by Choi et al. (1994) who showed an absence of correlation between the activity of the three chitin synthases and the transcript levels of the three corresponding genes. However, if very low levels of CHS mRNAs, as we observed in the presence of excess of Knr4p, are sufficient for normal growth, why then would the expression of chitin-synthase-encoding genes need to be so high in wild-type cells? We propose that in normal growth conditions, an excess of transcription of CHS genes leads to deposition of enzymes in cytoplasmic microvesicles named chitosomes (LealMorales et al., 1988, 1994), most likely in an inactive (zymogenic) form. Just prior to bud formation, or in response to environmental signals such as pheromones, these vesicles deliver their chitin synthases to the plasma membrane where they become activated. This process could be part of the cell wall repair mechanism which is activated in response to cell wall weakening, and which is characterized by an increase in chitin and in the crosslinking between $\beta$-glucan and chitin (Kapteyn et al., 1997; Popolo et al., 1997; Daran et al., 1997).

Whilst additional copies of KNR4 clearly reduced the expression of genes encoding the three chitin synthases, we did not find the product of this gene in the nucleus. Rather, using the powerful GFP technique allowing ' in vivo' visualization (Chalfie et al., 1994; Niedenthal et al., 1996), we found the GFP-Knr4p at the neck between mother and daugther cells in the early stages of budding, and in patches near the presumptive bud site in unbudded cells. Further work will be necessary to investigate in more detail the localization of $\mathrm{Knr} 4 \mathrm{p}$ during the life cycle and to compare it with that of other proteins involved in bud formation and chitin deposition (De Marini et al., 1997; Santos \& Snyder, 1997). The non-nuclear localization of $\mathrm{Knr} 4 \mathrm{p}$ in our experiments is in contrast with the data of Fishel et al. (1993) who isolated the same gene, designated $S M I 1$, in a screen for proteins that bind MAR (matrix-associated regions) on DNA, and found an intranuclear localization of Smi1p homologues in animal cells by indirect immunofluorescence using SMI1-antipeptide antibodies. The reason for nuclear localization of this protein is not clear, unless the antipeptide antibodies raised against an 18 amino acid basic-rich region located at the $\mathrm{C}$ terminus of the yeast Smi1p could react artefactually with nuclear material in animal cells. It is also not clear why these authors did not use these antibodies for immunofluorescence experiments in S. cerevisiae. We however can provide a convincing explanation of why SMI1/ KNR4 was isolated in a search for MAR-binding proteins. The screening of mutants affected in this binding was based on a temperature-sensitive inducible colour enhancement on X-Gal plates. The major drawback of this genetic approach is to isolate mutant cells highly permeable to the chromophore. Yeast cells mutated at the KNR4 locus actually displayed such a phenotype, even though quantitative assays of $\beta$-galactosidase performed on crude extract from knr4 mutants and wild-type cells were identical (Hong et al., 1994a; our unpublished result). Another intriguing difference between our results and those of Fishel et al. (1993) was our inability to observe a thermosensitive growth arrest phenotype with different strains.

The localization of Knr4p at the incipient bud site and bud neck is in good agreement with the fact that KNR4 was isolated by complementation of a mutant resistant to K9 killer toxin from $H$. mrakii (Hong et al., 1994a) whose cytocidal action has been shown to take place at the site of new bud appearance (Komiyama et al., 1996). In addition, this localization is very similar to that of proteins involved in chitin biosynthesis, including Chs3p, Chs4p and Bni4p (Santos \& Snyder, 1997; De Marini et al., 1997), suggesting that $\mathrm{Knr} 4 \mathrm{p}$ may be a component of this enzymic machinery. A main difference with these latter proteins is that Knr4p has an apparent symetrical distribution accross the neck. Such a localization makes this protein unlikely to act as a direct transcriptional repressor of CHS genes, but the fact that KNR4 affected all three CHS genes reveals for the first time the occurrence of a common regulatory mechanism. One possible explanation is that an excess of Knr4p can titrate a factor required for transcriptional regulation of genes encoding chitin synthases. Alternatively, Knr4p could be a component of a complex regulator involved in global regulation of cell wall assembly. Lack of this protein would disorganize this complex protein, leading to a decrease in $1,3-\beta$-glucan synthase activity and stimulation of chitin synthase, whereas an excess of this protein could have perturbating effects on as yet unknown components involved in the feedback regulation of genes encoding chitin synthases. Work is under way to investigate potential interactions of Knr4p with components of the chitin biosynthetic machinery and to unravel other potential partners.

\section{ACKNOWLEDGEMENTS}

We are grateful to Frans $M$. Klis (Free University of Amsterdam, The Netherlands), Enrico Cabib (NIH, Bethesda, MD, USA), Beth Didomenico (Shering-Plough Research Institute, NJ, USA) and J. H. Hegemann (Düsseldorf, Germany) for strains or plasmids. We thank Ton Timmers for help with fluorescence microscopy and critical reading of the manuscript, and Miss Amanda Pearce for proof-reading this manuscript. This work was supported in part by grant 960956 from the Région Midi-Pyrenées. H.M. holds a fellowship 
from INRA (Institut National de la Recherche Agronomique), France. A.D. is a post-doctoral fellow from CNRS (Centre National de la Recherche Scientifique), France.

\section{REFERENCES}

Appeltauer, U. \& Achstetter, T. (1989). Hormone-induced expression of the CHS1 gene from Saccharomyces cerevisiae. Eur J Biochem 181, 243-247.

Boeke, J. D., Trueheart, J., Natsoulis, G. \& Fink, G. R. (1987). 5Fluoro-orotic acid as a selective agent in yeast molecular genetics. Methods Enzymol 154, 164-175.

Brown, J. L., North, S. \& Bussey, H. (1993). SKN7, a yeast multicopy suppressor of a mutation affecting cell wall $\beta$-glucan assembly, encodes a product with domains homologous to prokaryotic two-component regulators and to heat shock transcription factors. J Bacteriol 175, 6908-6915.

Cabib, E., Shaw, J. A., Mol, P. C., Bowers, B. \& Choi, W.-J. (1996). Chitin biosynthesis and morphogenetic processes. In The Mycota III. Biochemistry and Molecular Biology, pp. 243-267, Edited by R. Bambl \& G. A. Marzluf. Berlin \& Heidelberg: Springer.

Chalfie, M., Tu, Y., Euskirchen, G., Ward, W. W. \& Prasher, D. C. (1994). Green fluorescent protein as a marker for gene expression. Science 263, 802-804.

Choi, W.-J., Santos, B., Duran, A. \& Cabib, E. (1994). Are yeast chitin synthases regulated at the transcriptional or the posttranslational level? Mol Cell Biol 14, 7685-7694.

Christianson, T. W., Sikorski, R. S., Dante, M., Shero, J. H. \& Hieter, P. (1992). Multifunctional yeast high-copy-number shuttle vectors. Gene 110, 119-122.

Cid, V. J., Duran, A., Del Rey, F., Snyder, M. P., Nombela, C. \& Sanchez, M. (1995). Molecular basis of cell integrity and morphogenesis in Saccharomyces cerevisiae. Microbiol Rev 59, 345-386.

Dallies, N., François, J. \& Paquet, v. (1998). A new method for quantitative determination of polysaccharides in the yeast cell wall. Application to the cell wall defective mutants of Saccharomyces cerevisiae. Yeast 14, 1297-1306.

Daran, J. M., Bell, W. \& François, J. (1997). Physiological and morphological effects of genetic alterations leading to a reduced synthesis of UDP-glucose in Saccharomyces cerevisiae. FEMS Microbiol Lett 153, 89-96.

De Marini, D. J., Adams, A. E. M., Fares, H., De Virgilio, C., Valle, G., Chaung, J. S. \& Pringle, J. R. (1997). A septin-based hierarchy of proteins required for localized deposition of chitin in the Saccharomyces cerevisiae cell wall. J Cell Biol 139, 75-93.

Douglas, C. M., Foor, F. Marrinan, J. A. \& 11 other authors (1995). The Sacchraomyces cerevisiae FKS1 (EGT1) gene encodes an integral membrane protein which is a subunit of 1,3- $\beta$-D-glucan synthase. Proc Natl Acad Sci USA 91, 12907-12911.

Drgonova, J., Drgon, T., Tanaka, K., Kollar, R., Chen, G.-C., Ford, R. A., Chan, C. S. M., Takai, Y. \& Cabib, E. (1997). Rholp, a yeast protein at the interface between cell polarization and morphogenesis. Science 272, 277-279.

Elorza, M. V., Rico, H. \& Sentandreu, P. (1983). Calcofluor white alters the assembly of chitin fibrils in Saccharomyces cerevisiae and Candida albicans cells. J Gen Microbiol 129, 1577-1582.

El-Sherbeini, M. \& Clemas, J. A. (1995). Cloning and characterization of GNS1: a Saccharomyces cerevisiae gene involved in synthesis of 1,3- $\beta$-D-glucan in vitro. J Bacteriol 177, 3227-3234.

Fishel, B. A., Sperry, A. O. \& Garrard, W. T. (1993). Yeast calmodulin and a conserved nuclear protein participate in the in vivo binding of a matrix association region. Proc Natl Acad Sci USA 90, 5623-5627.

Fleet, G. H. (1991). Cell walls. In The Yeasts, 2nd edn, pp. 199-278. Edited by A. H. Rose \& J.S. Harrison. London: Academic Press.

Gimeno, C. J., Ljundahl, P. O., Styles, C. A. \& Fink, G. R. (1992). Unipolar cell divisions in the yeast $S$. cerevisiae lead to filamentous growth regulation by starvation and RAS. Cell 68, 1077-1090.

Herscovics, A. \& Orlean, P. (1993). Glycoprotein biosynthesis in yeast. FASEB J 7, 540-550.

Hong, Z., Mann, P., Brown, N. H., Tran, L. E., Shaw, K. J., Hare, R. S. \& Didomenico, B. (1994a). Cloning and characterization of KNR4, a yeast gene involved in $(1,3)$ - $\beta$-glucan synthesis. Mol Cell Biol 14, 1017.

Hong, Z., Mann, P., Shaw, K. J. \& Didomenico, B. (1994b). Analysis of $\beta$-glucans and chitin in a Saccharomyces cerevisiae cell wall mutants using high-performance liquid chromatography. Yeast 10, 1083-1092.

Igual, J. C., Johnson, A. L. \& Johnston, L. H. (1997). Coordinated regulation of gene expression by the cell cycle transcription factor SWI4 and the protein kinase C MAP kinase pathway for yeast cell integrity. EMBO J 15, 5001-5013.

Inoue, S. B., Takewaki, N., Takasuka, T. \& 7 other authors (1995). Characterization and gene cloning of $1,3-\beta$-glucan synthase from Saccharomyces cerevisiae. Eur J Biochem 321, 845-854.

Kapteyn, J. C., Ram, A. F. J., Groos, E. M., Kollar, R., Montijn, R., Van Den Eende, H., Llobell, A., Cabib, E. \& Klis, F. M. (1997). Altered extent of cross-linking of $\beta 1,6$-glucosylated mannoproteins to chitin in Saccharomyces cerevisiae mutants with reduced cell wall $\beta 1,3$-glucan content. J Bacteriol 179, 6279-6284.

Kasahara, S., Yamada, H., Mio, T., Shiratori, Y., Miyamoto, C., Yabe, T., Nakajima, T., Ichishima, E. \& Furuichi, Y. (1994). Cloning of the Saccharomyces cerevisiae gene whose overexpression overcomes the effects of HM-1 killer toxin, which inhibits $\beta$ glucan synthesis. J Bacteriol 176, 1488-1499.

Klis, F. M. (1994). Cell wall assembly in yeast. A review. Yeast $\mathbf{1 0}$, 851-890.

Kollar, R., Reinhold, B. B., Petrakova, E., Yeh, H. J. C., Ashwell, G., Drgonova, J., Kapteyn, J. C., Klis, F. M. \& Cabib, E. (1997). Architecture of the yeast cell wall. $\beta(1 \rightarrow 6)$-glucan interconnects mannoprotein, $\beta(1 \rightarrow 3)$-glucan, and chitin. J Biol Chem 272, 17762-17775.

Komiyama, T., Ohta, T., Urakami, H., Shiratori, Y., Takasuka, T., Satoh, M., Watanabe, T. \& Furuichi, Y. (1996). Pore formation on proliferating yeast Saccharomyces cerevisiae cell buds by HM-1 killer toxin. J Biochem 119, 731-736.

Leal-Morales, C., Bracker, C. E. \& Bartnicki-Garcia, S. (1988). Localization of chitin synthase in cell-free homogenates of Saccharomyces cerevisiae: chitosomes and plasma membrane. Proc Natl Acad Sci USA 85, 8516-8520.

Leal-Morales, C. A., Bracker, C. E. \& Bartnicki-Garcia, S. (1994). Subcellular localization, abundance and stability of chitin synthetases 1 and 2 from Saccharomyces cerevisiae. Microbiology 140, 2207-2216.

Lussier, M., White, A.-M., Sheraton, J. \& 17 other authors (1997). Large scale identification of genes involved in cell surface biosynthesis and architecture in Saccharomyces cerevisiae. Genetics 147, 435-450.

Mazur, P., Morin, N., Baginsky, W., El-Sherbeini, M., Clemas, J. A., Nielsen, J. B. \& Foor, F. (1995). Differential expression and function of two homologous subunits of yeast $1,3-\beta$-D-glucan synthase. Mol Cell Biol 15, 5671-5681. 
Mewes, H. W., Albermann, K., Bähr, M. \& 9 other authors (1997). Overview of the yeast genome. Nature 387, 7-65.

Niedenthal, R. K., Riles, L., Johnston, M. \& Hegemann, J. H. (1996). Green fluorescent protein as a marker for gene expression and subcellular localization in budding yeast. Yeast 12, 773-786.

Paravicini, G., Cooper, M., Friedli, L., Smith, D. J., Carpentier, J. L., Klig, L. S. \& Payton, M. A. (1992). The osmotic integrity of the yeast cell requires a functional PKC1 gene product. $\mathrm{Mol}$ Cell Biol 12, 4896-4905.

Pompon, D., Louerat, B., Bronne, A. \& Urban, P. (1996). Yeast expression of animal and plant P540s in optimized redox experiments. Methods Enzymol 272, 51-64.

Popolo, L., Gilardelli, D., Bonfante, P. \& Vai, M. (1997). Increase in chitin as an essential response to defects in assembly of cell wall polymers in the ggp1s mutant of Saccharomyces cerevisiae. $J$ Bacteriol 179, 463-469.

Qadota, H., Python, C. P., Inoue, S. B., Arisawa, M., Anraku, Y., Zheng, Y., Watanabe, T., Levin, D. \& Ohya, Y. (1997). Identification of yeast Rho1p GTPase as a regulatory subunit of 1,3$\beta$-glucan synthase. Science 272, 279-281.

Ram, A. F. J., Wolters, A., Hoopen, R. T. \& Klis, F. M. (1994). A new approach for isolating cell wall mutants in Saccharomyces cerevisiae by hypersensitivity to calcofluor white. Yeast 10, 1019-1030.

Ram, A. F. J., Brekelmans, S. S. C., Oehlen, L. J. W. M. \& Klis, F. M. (1995). Identification of two cell cycle-regulated genes affecting the 1,3- $\beta$-D-glucan content of cell walls in Saccharomyces cerevisiae. FEBS Lett 358, 165-170.

Roberts, R. L. \& Fink, G. R. (1994). Elements of a single MAP kinase cascade in Saccharomyces cerevisiae mediate two developmental programs in the same cell type: mating and invasive growth. Genes Dev 8, 2974-2985.

Robzyk, K. \& Kassir, Y. (1992). A simple and highly efficient procedure for rescuing autonomous plasmids from yeast. Nucleic Acid Res 20, 3790.

Roncero, C. \& Duran, A. (1985). Effect of calcofluor white and congo red on fungal cell wall morphogenesis. In vivo activation of chitin polymerization. J Bacteriol 163, 1180-1185.

Rose, M. D., Novick, P., Thomas, J. H., Botstein, D. \& Fink, G. R. (1987). A Saccharomyces cerevisiae genomic plasmid bank based on a centromere-containing shuttle vector. Gene 60, 237-243.

Santos, B. \& Snyder, M. (1997). Targeting of chitin synthase 3 to polarized growth sites in yeast requires Chs5p and Myo2p. J Cell Biol 136, 95-110.

Santos, B., Duran, A. \& Valdivieso, H. (1997). CHS5, a gene involved in chitin synthesis and mating in Saccharomyces cerevisiae. Mol Cell Biol 17, 2485-2496.

Schietsl, R. H. \& Gietz, R. D. (1989). High efficiency transformation of intact yeast cells using single stranded nucleic acid as a carrier. Curr Genet 16, 339-346.

Siderius, M., Rots, E. \& Mager, W. H. (1997). High osmolarity signalling in Saccharomyces cerevisiae is modulated in a carbon source-dependent fashion. Microbiology 143, 3241-3250.

Sikorski, R. S. \& Hieter, P. (1989). A system of shuttle vectors and yeast host strains designed for efficient manipulation of DNA in Saccharomyces cerevisiae. Genetics 122, 19-27.

Trilla, J. A., Cos, T., Duran, A. \& Roncero, C. (1997). Characterization of CHS4 (CAL2), a gene of Saccharomyces cerevisiae involved in chitin biosynthesis and allelic to SKT5 and CSD4. Yeast 13, 795-807.

Valentin, E., Herrero, E., Rico, H., Miragall, F. \& Sentandreu, R. (1987). Cell wall mannoproteins during the population growth phases in Saccharomyces cerevisiae. Arch Microbiol 148, 88-94.

Yabe, T., Yamada, T., Kasahara, S., Furuichi, Y., Nakajima, T., Ichishima, E., Arisawa, M. \& Yamada-Okabe, H. (1996). HKR1 encodes a cell surface protein that regulates both cell wall $\beta$ glucan synthesis and budding pattern in the yeast Saccharomyces cerevisiae. J Bacteriol 178, 477-483.

Received 29 May 1998; revised 27 July 1998; accepted 14 September 1998. 